\title{
Numerical Simulation Analysis of Rigid Permeable Plate Embedded in Abutment Back
}

\author{
Li Dong $^{1 *}$, Yue Gong ${ }^{1}$ and Yi Zhang ${ }^{2}$ \\ ${ }^{1}$ College of Civil Engineering and Architecture, Shandong University of Science and Technology, Qingdao, 266590, China \\ ${ }^{2}$ College of Civil Engineering, Shangqiu Institute of Technology, Shangqiu, 476000, China
}

\begin{abstract}
In order to solve the problem of bumping at bridge head of bridges in our country and reduce the void volume of bridge end transition slab, the method of embedding rigid permeable plates is proposed in this paper. Combined with different engineering situations and using geotechnical engineering stress and strain professional analysis software SIGMA/W to model, the performance and engineering applicability of rigid permeable plates are numerically simulated. The results show that the bearing capacity of rigid permeable plate meets the engineering load requirements and is in line with the engineering applicability; Embedding rigid permeable plate can effectively reduce the void volume of bridge end transition slab, especially when the compactness of abutment back is lower, the effect of rigid permeable plate on reducing the void volume of bridge end transition slab is more obvious. The proposed method of embedded rigid permeable plate provides valuable theoretical and scientific basis for solving the problem of bridge head jumping.
\end{abstract}

\section{Introduction}

With the rapid economic growth in our country, the traffic volume and the heavy load of vehicles are increasing gradually, which puts forward more stringent requirements on the bearing capacity and safety performance of bridges. However, due to differential settlement caused by foundation conditions, filling materials, design and construction, etc., a certain height of staggered abutment is generated between abutment and embankment on the back of abutment. when the height of the step reaches a certain limit, strong bumpy feeling will occur when vehicles pass through here, causing vehicles to jump at the bridge head [1]. According to the survey data at home and abroad, about $25 \%$ of Bridges and culverts (about 150,000 Bridges, culverts, passageways and other structures) in the United States are affected by the jump cars at the bridge head, and the annual maintenance cost is up to 100 million us dollars [2-4]. Our country jumps over the maintenance management respect of car in bridge head equally costly huge, the charge of transition section of maintenance management of national freeway average annual average is in at least 100 million RMB above [5]. In order to reduce the maintenance cost and alleviate the harm of bridge head car jumping, geogrid and bridge head board have been widely used in recent years at home and abroad to prevent the problem of bridge head car jumping on highways, and a series of theoretical studies and tests have been carried out. Two scholars, X.M.Shi and C.S.Cai, respectively established the three- dimensional finite element analysis model of bridge end transition slab in 2004 to study and analyze the damage state of bridge end transition slab when bridge end transition slab and the lower foundation were separated from each other [6-7]. In 2004, Jonathan l.obison started to establish the finite element analysis model of the slab and the roadbed to study the stress and deformation of the slab and the roadbed as a whole, and compared and analyzed the finite element results with the field measured results[8]. In 2007, Roy S et al. made a nonlinear analysis of the stress deformation of bridge head slab under the action of load [9]. In 2006, niu sicheng carried out indoor model test on the disposal technology of geogrid wedge-shaped flexible slab, and systematically analyzed the mechanism of geogrid wedge-shaped flexible slab and the effect of disposal and reinforcement [10]. In 2006, scholar Yang xuexiang obtained the distribution of subgrade reaction force of the beam on winkler elastic foundation by solving the problem, and put forward the theory of winkler subgrade beam to analyze the problem of bridge head car jumping [11]. In 2007, Qu Zhanhui, Xie Yongli and others analyzed the action mechanism of flexible strap disposal measures between transition sections, and based on this, proposed the layout mode of flexible strap in transition section, deduced the calculation formula of layer spacing of flexible strap, and gave the determination method of relevant design parameters of flexible strap [12].

In this paper, based on the K141+970 middle bridge in the expansion project of yunnan xiaomo highway, the background data and data sampling survey of the local project are taken as reference, and the stress and strain

"Corresponding Author: Li Dong; email: 919256862@qq.com 
analysis software SIGMA/W is adopted to analyze and demonstrate the feasibility of the bridge abutment with the embedded rigid permeable plate.

\section{The rigid permeable plate method was proposed}

At present, in order to alleviate the problem of bumping at the bridge head, bridge end transition slab is widely installed at the bridge head section of expressways in our country. However, as the filled soil around the abutment back is generally not fully compacted, the embankment at the bridge head will be consolidated and settled under the action of vehicle load and the self-weight of the embankment, leading to the bottom of the slab being empty and the slab breaking. After the slab breaking, the settlement difference between the abutment and the embankment still exists, and the problem of bridge head jumping car still exists. In order to solve this problem, this paper puts forward that the rigid previous plate is installed in the fill of the back of the abutment, which can reduce the differential settlement between the abutment and the embankment, effectively control the amount of clearance of the bottom of the abutment, and prevent the rupture of the abutment.

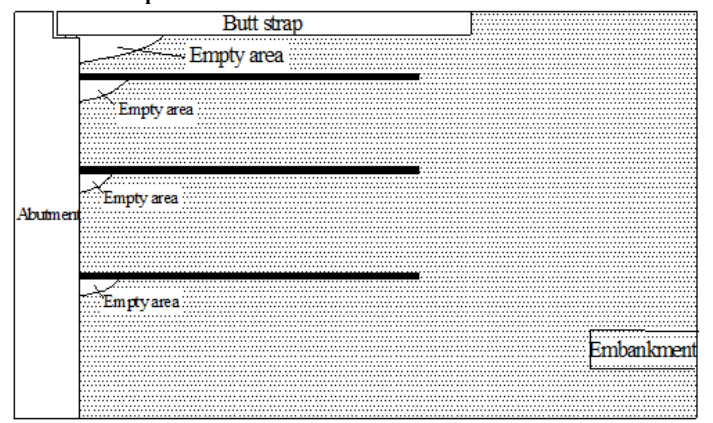

Figure 1. Schematic diagram of embedded rigid permeable plate
Specific measures: a layer of PVC plastic plate with considerable rigidity is embedded at certain depth under the back of the abutment and the bridge end transition slab (as shown in Figure 1, the black part is a rigid permeable plate), and several layers are embedded as much as possible. The rigid permeable plate is provided with fine holes to facilitate the seepage of water in the fill, thus reducing the deformation of the rigid permeable plate under the action of the fill pressure and further ensuring the rigidity requirement of the rigid permeable plate. The principle of the rigid permeable plate for preventing the slab from falling off is as follows: on the one hand, the rigidity of the bridge head embankment is increased, the rigidity difference between the bridge head and the embankment is reduced, and the differential settlement between the bridge and the road transition section is facilitated to be reduced; On the other hand, due to the considerable rigidity of this permeable PVC plastic plate, after several layers of rigid permeable plates are embedded in the bridgehead embankment, the void volume in the lower part of bridge end transition slab is limited to that between the top layer of rigid permeable plate and the upper soil body and the lap plate, thus greatly reducing the void volume of the original lap plate (see Figure 1 for schematic diagram).

\section{Numerical simulation analysis of embedded rigid permeable plate method}

\subsection{Engineering background}

The bridge transition slab is $8 \mathrm{~m}$ long and $30 \mathrm{~cm}$ thick, the longitudinal slope of the slab is flat, the underground water level of the project is $5 \mathrm{~m}$ on average.

Table 1. Physical and Mechanical Parameters of Embankment Fill.

\begin{tabular}{c}
$\begin{array}{c}\text { Category of } \\
\text { soil }\end{array}$ \\
\hline
\end{tabular}

Silty clay

$\begin{array}{cc}\text { Unit } & \text { Modulus of } \\ \text { weight } & \text { elasticity } \\ (\mathrm{kN} / \mathrm{m} 3) & (\mathrm{kPa})\end{array}$

20
2000
Poisson ratio

0.32

Cohesive
force
$(\mathrm{kPa})$

5
Angle of friction $\left(^{\circ}\right)$

15
Dilatancy angle $\left(^{\circ}\right)$

\subsection{Establishment of Numerical Model}

According to the structure form and geological condition of the actual project and based on the stress and strain analysis software SIGMA/W of geotechnical engineering, this paper analyzes and studies the problem of the rigid permeable plate in solving the problem of the bridge head overlaying. As shown in Figure 2.

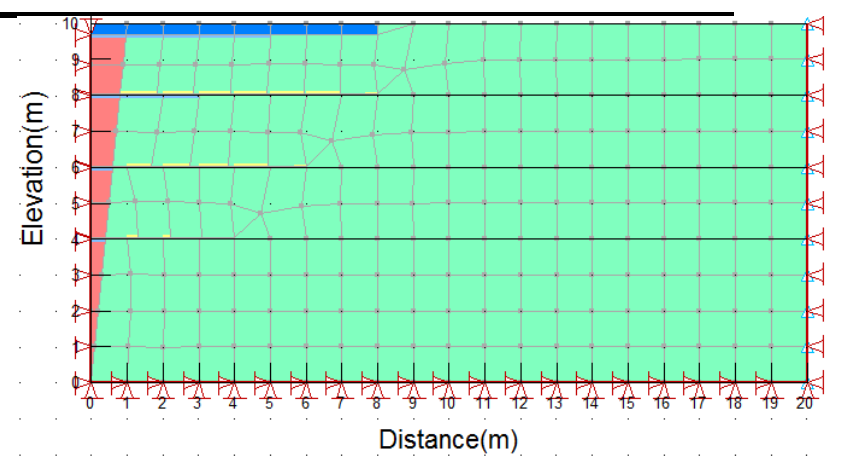

Figure 2. Finite Elemmodeent 1

The model will now be described in detail as follows: (1) According to the actual abutment height, take the embankment height as 10m; Considering the influence of 
the arrangement length of embedded rigid permeable plates and boundary conditions on the calculation results, the abutment embankment takes $20 \mathrm{~m}$ as the calculation length; (2) $\mathrm{X}=0$ interface represents abutment back; (3) Based on the fact that the fill near the abutment back of the bridge transition section is generally not fully compacted, the red triangle area in the figure represents the soil with low degree of compaction (inclination 1/10), and the light green area in the figure represents the soil with high degree of compaction; (4) according to the actual size of bridge head laps, take the blue area in the figure as the bridge head laps, with a length of $8 \mathrm{~m}$ and a thickness of $30 \mathrm{~cm}$; (5) considering that the thicker the fill, the smaller the strain of the soil will be, so the rigid permeable plate need not be set too long. Therefore, at the height of $4 \mathrm{~m}, 6 \mathrm{~m}$ and $8 \mathrm{~m}$ of the embankment, a rigid permeable plate with a length of $4 \mathrm{~m}, 6 \mathrm{~m}$ and $8 \mathrm{~m}$ is set for three layers respectively; (6) Each layer of rigid permeable plate has no connection with the back of the platform; (7) Through the market investigation of PVC plastic board, the elastic modulus of PVC plastic board in the market can basically reach $3.95 \mathrm{MPa}$. Considering the convenience and stability of embedding in the fill, the elastic modulus of rigid permeable board in the model is set at $3.95 \mathrm{MPa}$ and the thickness is set at $3 \mathrm{~cm}$; (8) in order to prevent the joint settlement of the rigid permeable plate and the soil mass, interface elements are set between the overlap plate and the soil mass and between the rigid permeable plate and the soil mass below. The elastic modulus and bulk density of the interface elements are set to zero; (9) Boundary conditions: the left boundary $\mathrm{X}=0$, the bridge head slab is hinged with the back of the platform, allowing in-plane rotation; The right boundary $\mathrm{X}=0$ is the potential seepage surface. Lower boundary $\mathrm{X}=0$ and $\mathrm{Y}=0$; (10) The water level is at $\mathrm{Y}=5 \mathrm{~m}$.

\section{Feasibility analysis of embedded rigid permeable plate method}

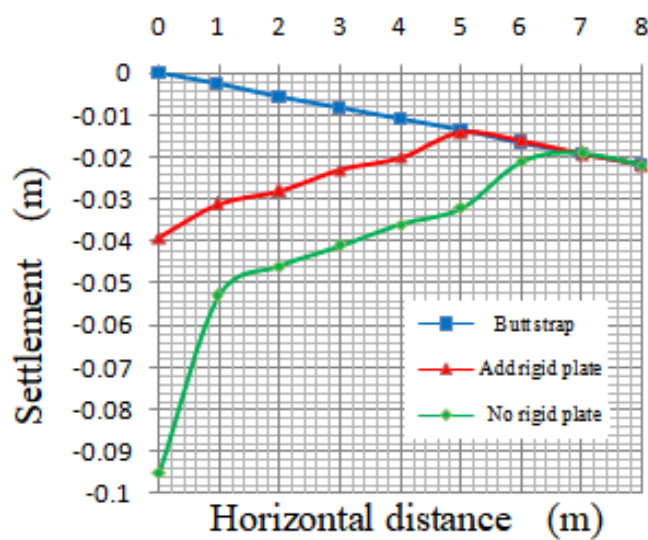

Figure 3. settlement curve when the compaction degree of fill near abutment is $84 \%$
The purpose of the embedded rigid permeable plate method is to reduce the void volume at the bottom of the bridge end transition slab plate. Therefore, the feasibility of the method is to judge whether the method can effectively reduce the void volume under the bridge end transition slab under normal working conditions. Based on the fact that the filling soil near the abutment back is not fully compacted in the roadbed construction process[13], the compaction degree of the soil near the abutment back in the numerical model is reduced, and the settlement curve of the bridge head slab and the soil below is obtained under the action of the self-weight of the embankment and seepage consolidation. Comparing the settlement curve with rigid permeable plate and without rigid permeable plate, the void volume under bridge end transition slab and the effect of embedding rigid permeable plate on reducing the void volume of lap plate can be analyzed. The model calculated respectively in the embankment under the action of gravity and the seepage consolidation, abutment table near the back part of the filled soil compaction degree $84 \%, 88 \%, 92 \%, 96 \%$ and $100 \%$, embedded rigid waterproof board with no rigid waterproof board embedded in both cases the bridge below the strap and the settlement curve of soil, seepage consolidation time is set to 2 years(according to the practical experience of local road maintenance personnel, consolidation and settlement of bridge head in local bridge road transition section are basically completed within 2 years).

Because the simulation analysis only analyzes the differential settlement of abutment and embankment, it is assumed that the settlement of abutment is zero. The elastic modulus of the slab was set as $30000 \mathrm{MPa}$, the bulk weight was $24 \mathrm{kN} / \mathrm{m}^{3}$, and the poisson's ratio was 0.24. In the model, the beam element was used for calculation and analysis

The settlement curves and stress nephogram of the model of five groups of soils under bridge end transition slab and bridge end transition slab are obtained through software simulation calculation as shown in Figure 3Figure 8 .

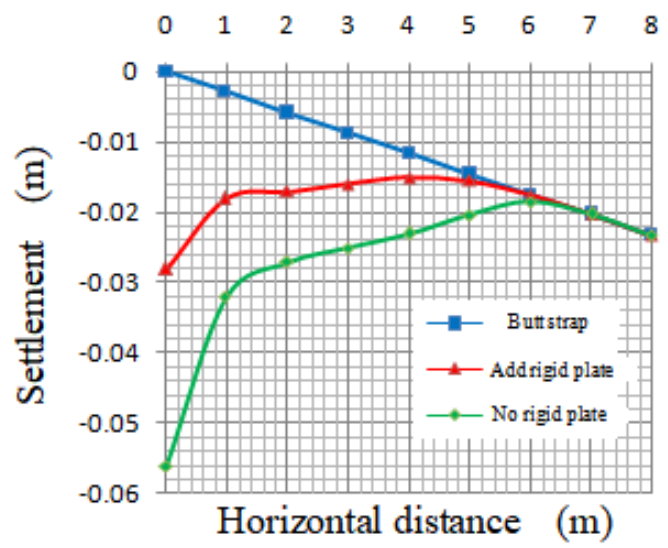

Figure 4.settlement curve when the compaction degree of fill near abutment is $88 \%$ 


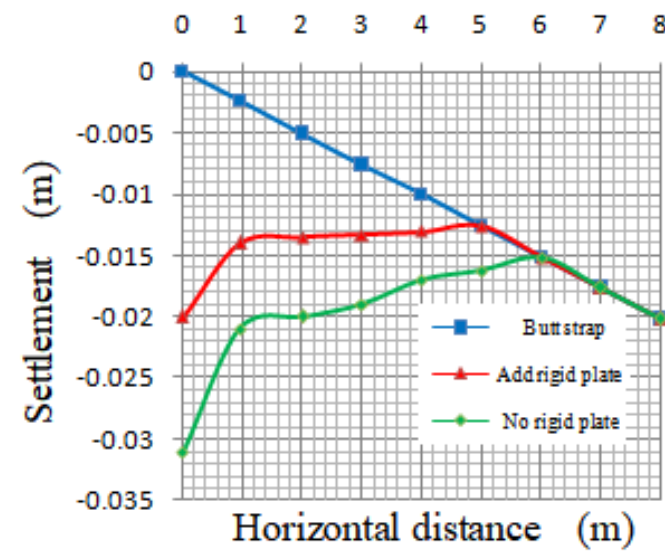

Figure 5. Settlement curve when the compaction degree of fill near abutment is $92 \%$

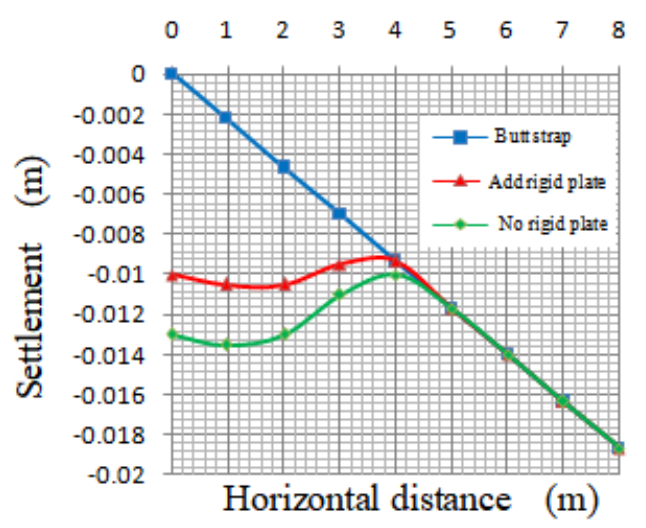

Figure 7. Settlement curve when the compaction degree of fill near abutment is $92 \%$

Will now embedded rigid waterproof board with no embedded rigid waterproof board as a two different engineering conditions, two kinds of working conditions of surface settlement curve between area and without embedded rigid waterproof board bridge strap below the soil settlement curve and the bridge of the strap area formed by the subsidence curve of ratio calculation, this ratio as a percentage of effective embedded rigid waterproof board. According to the analysis in Figure 3 to Figure 7, the number of small and medium squares in each region is denoted as its area, thus the effective percentage of rigid permeable plate in these six cases can be obtained. When the compaction degree of some soil near the abutment is $84 \%, 88 \%, 92 \%, 96 \%$ and $100 \%$

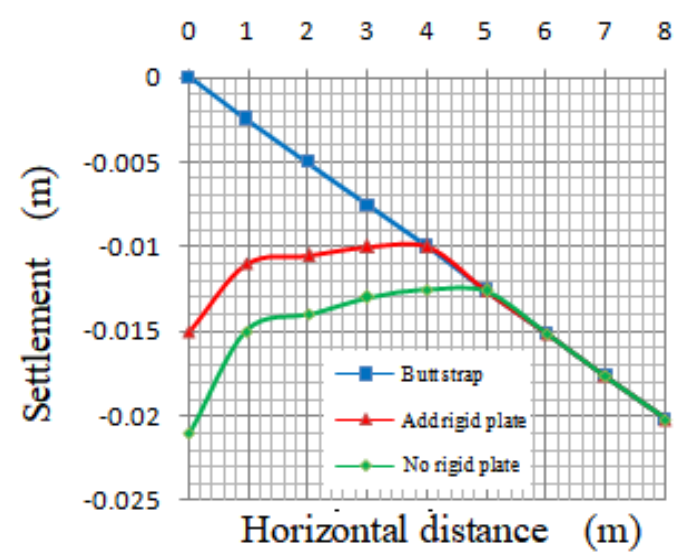

Figure 6. Settlement curve when the compaction degree of fill near abutment is $96 \%$

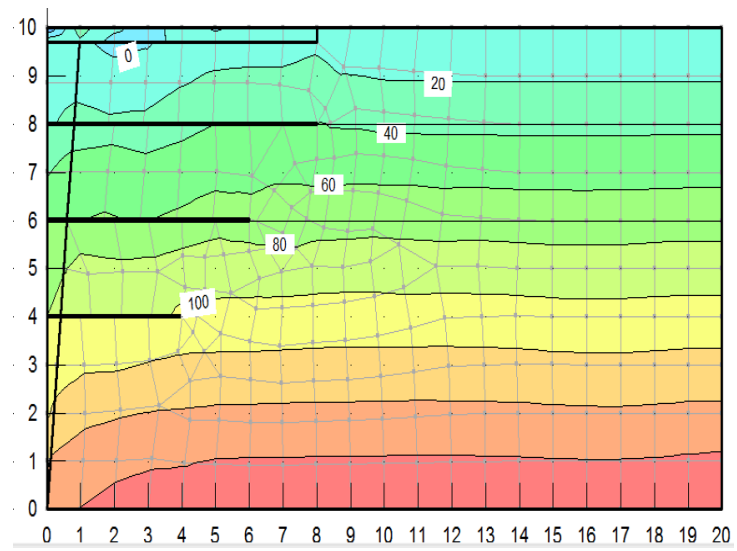

Figure 8. Stress nephogram of model

respectively, the effective percentage of the embedded rigid permeable plate is shown in Table 2. It can be concluded from Table 2 that when the compaction degree of the filled soil near the abutment abutment is smaller, the effect of the embedded rigid permeable plate on reducing the bottom of the abutment is more obvious. According to the actual engineering data, the compaction degree of the filled soil near the abutment back can basically reach about $88 \%$. According to the analysis and calculation in Figure 4, the effective percentage of the embedded rigid permeable plate is $60 \%$. According to the above effective percentage, the embedded rigid permeable plate method can play a significant role in the current highway engineering construction methods.

Table 2. Effective percentage of embedded rigid permeable plates

\begin{tabular}{cccccc}
\hline $\begin{array}{c}\text { Degree of } \\
\text { compaction }\end{array}$ & $84 \%$ & $88 \%$ & $92 \%$ & $96 \%$ & $100 \%$ \\
\hline $\begin{array}{c}\text { Effective } \\
\text { percentage }\end{array}$ & $75 \%$ & $60 \%$ & $54 \%$ & $40 \%$ & $27 \%$ \\
\hline
\end{tabular}

\section{Conclusion}

According to the structure form and geological condition of the actual project and based on the stress and strain analysis software SIGMA/W of geotechnical engineering, this paper analyzes and studies the problem of the rigid permeable plate in solving the problem of the bridge head overlaying. The software was used to establish the model for relevant numerical simulation. From the engineering applicability of the rigid permeable plate, the influence of the rigid permeable plate on the void amount of the bridge head slab was studied, and the following conclusions were obtained: The analysis of the two cases with and without embedded rigid previous plate shows that the method of embedded rigid previous plate can 
effectively reduce the void of the bridge head slab, and thereby reduce the occurrence of the bridge head jump vehicle disease. In particular, the smaller the abutment back compaction degree is, the more significant the effect of reducing the void of the bridge head slab is.

\section{Acknowledgment}

This study was financially supported by the Project of Science and Technology Innovation Fund for graduate students of the Shandong University of Science and Technology (no. SDKDYC180212).

\section{References}

1. Wu, F. Q., Wang, G. H., Liao, B. H., Huang, Y. L. (2014) Research on the Causes of Bump at Bridgehead in Highway Traffic. J. Highway., 7:90-94.

2. Azechi, G., Nishitani, N., Kokubun, K. (2003) Countermeasures to fill the void under cushion slab of a bridge abutment. J. Foundation Engineering and Equipment., 31(6): 79-81.

3. Paixão, A., Fortunato, E., Calçada, R. (2015) The effect of differential settlements on the dynamic response of the train-track system: A numerical study. J. Engineering structures., 88: 216-224.

4. Zhao, S. Q. (2009) Research on Prevention and Treatment Technology of Bump at Bridge Head. D. Shandong university.

5. Ding, W. Y., Liu, Q., Liu, H. X. (2014) On Causes Analysis, Condition Evaluation and Treatment Technology for Bumping at Bridge Head. J. Subgrade Engineering., 3:17-21.

6. Shi, X. M., Cai, C. S. (2004) Finite element analysis of concrete approach slab on soil embankment. J. Geotechnical Engineering for Transportation Project., 126:393-402.

7. Cai, C. S., Shi, X. M. (2005) Structural performance of bridge approach slabs under given embankment settlement. J. Journal of Bridge Engineering., 10(4):482-489.

8. Robison, J. L., Luna, R. (2004) Deformation Analysis of Modeling of Missouri Bridge Approach Embankments. J. Geo Trans., 2020-2027.

9. Roy, S., Thiagarajan, G. (2017) Nonlinear finiteelement analysis of reinforced concrete bridge approach slabs. J. Journal of Bridge Engineering., 12(6):801-806.

10. Niu, S. S. (2006) Study on Technique of Treatment for Jump at Back of Abutment in Loess Area By the Flexible Approach Slab. D. Chang' an university.

11. Yang, X. X. (2006) The Feature of Foundation Pressure on Winkler Foundation-Beam With One Fixed End and Its Application. J. Engineering Mechanics., 23(11):76-79.

12. Qu, Z. H., Yang, X. H., Xie, Y. L. (2007) Design Method of Flexible Approach Slab at Bridge
Abutment. J. China Journal of Highway and Transport., (1):19-23.

13. Sun, B. (2010) Mechanism Analysis and Experimental Study on Treatment Methods for Bump at Bridge Head of Built Soft Foundation Bridge. D. Zhejiang University. 